\title{
ТЕМА ЕДИНСТВА СОЗНАНИЯ В СОВРЕМЕННЫХ ФИЛОСОФСКИХ И НАУЧНЫХ ИССЛЕДОВАНИЯХ
}

Исследование выполнено при финансовой поддержке РФФИ (проект № 19-

013-00816)

Акопов Г.В. (Самарский государственный сочиально-педагогический

университет, Самара, Россия)

akopovgv@gmail.com

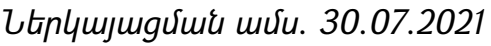

9pupunuर्umध uर्u. 07.08.2021

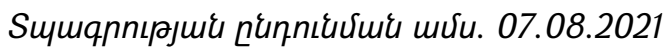

В статье рассматривается проблема единства сознания в контексте современных исследований сознания. Представлены различные точки зрения, связанные с разными подходами к идентификации сознания и определению его структуры. Анализируется решение проблемы единства сознания, представленное в монографии Tim'a Bayne в сопоставлении с другими. Обозначен авторский подход к решению проблемы единства сознания в логике социально-коммуникативной парадигмы и двухфакторной модели сознания. Показана возможность широкой актуализации проблемы единства сознания не только на индивидуальном уровне сознания, но и в микро-, мезо-, макро-групповом измерениях.

Ключевые слова: единство сознания, теории сознания, феноменальное сознание, субъективность, репрезентация, коммуникация, инстаурация.

DOI: https://doi.org/10.46991/SBMP/2021.4.2.011

Проблема сознания в XXI веке становится общим центром естественных, социальных и гуманитарных наук. Широта и многомерность исследовательских усилий в этой области [1] определяют особую сложность восприятия, объяснения и применения различных концепций сознания в конкретных условиях реальной жизни. Одновременно, как отмечает А.П. Назаретян, с развитием технологий возрастает потенциальный эффект индивидуальных действий и тем самым снижается внутренняя устойчивость общества, для обеспечения которой требуются все более совершенные «культурные самоограничения» [2]. В связи с этим, проблема единства сознания в социальной жизни выходит на первый план. Драматические события последних лет, связанные с ковидной пандемией, расовым неравенством, сменой поколений в тоталитарных обществах и др., отчетливо демонстрируют опасности нарушения единства сознания в социальном измерении. Вместе с тем, как считает Ю.М. Лотман, «гетерогенность является исконным свойством человеческого сознания, для 
механизма которого существенно необходимо наличие хотя бы двух не до конца «взаимопереводимых систем» [3, с. 534]. Следует отметить, что к «взаимопереводимым системам», помимо феноменов культуры, автор относит также ментальные структуры, основанные на языковом сознании, т.е. речевом, а также сенсорно-перцептивном, когнитивном, эмоциональном, поведенческом и др. образующих сознания.

Новые дефиниции сознания, в частности, с позиции функционализма: репрезентация (representation) [13], «сознание доступа» (Access-consciousness) [7]; биологический натурализм [15]; когнитивный плюрализм [11] и т.д., обусловили возможности конкретной унитарной либо множественной реализации единства сознания. В этом контексте отметим также работы T. Honderich'a [10] и R. Gennaro [9]. В первой, с позиций фризикализма отстаивается единство сознания в универсальном варианте фактического, т.е. «обычного" сознания (ordinary consciousness) [10]. Противоположная версия отстаивается в работе Gennaro, продолжающего линию Д. Розенталя в развитии метапсихологической теории сознания, основанной на идее о «мышлении высшего порядка» (Higher - order thought) [9]. О высших психических фрункциях, как известно, писал Л.С. Выготский, рассматривая возникновение и развитие сознания с позиции культурно-исторической психологии. Работа Gennaro основана на положениях репрезентационализма, обновленного проблематикой сознания нового времени. Репрезентационализм, по нашему мнению, позволяет ответить на вопрос о единой форме множества языков сознания: телесное, сенсорноперцептивное, когнитивное, афрфективное и др. виды сознания, существующие параллельно с речевым сознанием, на который не всегда легко «перевести» содержание других языков сознания [1].

Принятие категории "репрезентация» в качестве «центрального понятия когнитивной науки, философии, логики и психологии может дать ключ к тайне сознания» [8, с. 568]. И в этом случае, как нам представляется, единство сознания обеспечивается монокатегориальной основой репрезентативной теории сознания. Если в унитарной парадигме сознания тема единства сознания в полной мере охватывалась данным понятием, то в междисциплинарных комплексных исследованиях, в частности, нейрокогнитивного характера, возникла необходимость интегративного описания процессов возникновения и проявления сознания. В англоязычной литературе в качестве такого понятия используется термин "binding", не имеющий аналогов в русскоязычной литературе по проблеме сознания. Не калькируя данный термин, мы далее используем аббревиатуру БНД-проблема, подразумевая процесс, либо механизм обеспечения целостности, интегрированности мозговой и преднамеренной активности в сенсорной, перцептивной, афффективной, когнитивной и других фрормах, идентифицируемых исследователями в качестве тех или иных 
типов и видов сознания. Как пишет A. Revonsuo, некоторые исследователи считают решение БНД-проблемы ключом к решению проблемы сознания (психофизическая проблема), отмечая также различные аспекты БНДпроблемы [14]. Психологический аспект, когда различные объекты восприятия, которые могут быть не связаны между собой в физическом пространстве, оказываются объединенными в некоторую целостность в перцептивном сознании индивида. В этом случае БНД-проблема эквивалентна проблеме единства сознания. Однако БНД-проблема существует и в нейронауке, не в полной мере дающей ответ на вопрос как интегрируется активность огромного числа нейронов, процессов в нейросетях для обеспечения перцепции, мышления и других модусов сознания [14]. В когнитивной науке этот же вопрос интеграции в контексте БНД-проблемы связан с процессами соединения информации, поступающей от различных сенсорных модулей, независимых друг от друга (цвет, фрорма, движение и т.д.), а также интеграция для фрункций селективного внимания, принятия решений, воспроизводящей памяти, контроля взаимодействия с окружающей средой, репрезентации объектов и др. [14]. БНД может иметь место также в неосознаваемом поведении, например, в прайм-эфрфектах, в так называемых явлениях «слепого видения» и др. Не дифференцируя проблемы БНД и единства сознания, Revonsuo выделяет локальное и глобальное единства, акцентируя отсутствие объяснения процессов, обеспечивающих единство, главным образом, в отношении феноменального сознания [14].

Как отмечалось выше, понятие феноменального сознания, центрированное в фрилософской литературе о сознании, в связи с упомянутым «объяснительным пробелом», т.е. невозможностью объяснить возникновение и проявления сознания, отталкиваясь от закономерностей физического мира, не вписывается в систему знаний о Мире, нарушая тем самым глобальное единство научного сознания.

В фундаментальной, многоаспектной работе Т. Вауnе, посвященной проблеме единства сознания (автор является также соредактором энциклопедического издания по проблеме сознания [6]), изначально обсуждает вариативность единства (различные виды) и в качестве основополагающего вида рассматривает «феноменальное единство» сознания, означающее «объединенность сознания» [6, с.3]. Следует отметить, что автор относит себя к тем исследователям сознания, которые не считают необходимым выделять помимо френоменального сознания также "рациональное» (когнитивноепсихологическое по Чалмерсу) сознание. Однако, фрилософские определения феноменального сознания представляются не вполне ясными, в особенности для перевода с английского на русский язык. В глоссарии книги Ревонсуо 
феноменальное сознание определяется как "базовая форма сознания», состоящая из субъективных переживаний и квалиа, существует независимо от языка и более высоких когнитивных фрункций [4, с. 326]. В свою очередь «квалиа» определяется как «простейшие компоненты феноменального переживания» [4, там же]. Термином «переживание» в этих определениях, по-видимому, обозначается то, что в англоязычной философской и научной литературе номинировано словом “ехреrience”, т.е. «опыт», а в контексте сознания ментальный или психический опыт сознания, возможно, осознания. Как отмечает А. Ревонсуо, все сознательные состояния, согласно репрезентационализму, суть репрезентативные состояния, т.е. «состояния, несущие информацию о внешних объектах или событиях» [4, с. 217]. Вместе с тем, репрезентации могут носить внутренний характер (inner representation), В частности, само-репрезентации (self-representation).

В книге Чалмерса феноменальное сознание определяется противопоставлением психологическому (когнитивному) сознанию и, таким образом, проводится отчетливая граница между фрилософрским и психологическим определениями [5].

Большую ясность в определение феноменального сознания находим в книге Irian Kriegel [12]. Ссылаясь на N. Block'a, автор констатирует множественность трактовок исходного понятия «сознание»: «феноменальное сознание», «сознание доступа» (access consciousness), «атенционное сознание» (monitoring consciousness), «самосознание» (self-consciousness) [12, с. 2]. Заметим, что к этому перечню можно также добавить «пять ведущих идей», определяющих сознание в книге Honderich'а: квалиа, интенциональность, субъективность, «то, на что это похоже» (What it is like) и, конечно, френоменальное сознание [10]. Критически относясь к плюрализму в трактовках сознания, Kriegel считает, что полное описание феноменального сознания должно включать "две характеристики сознания: качество ментального опыта и его субъективность» [12, с. 1]. Качественная характеристика связана с репрезентацией внешнего окружения, а субъективная характеристика сознания определяется репрезентацией субъектом самого себя тем или иным подходящим способом [12, с. 2].

Возвращаясь к работе Вауnе, рассматривающего все проявления сознания в категориальном пространстве [1] френоменального сознания, вводящего понятие «феноменальное единство», отметим также позицию автора в отношении противопоставления сенсорно-перцептивного, как и аффективного модусов френоменального сознания с мышлением, которое некоторые теоретики не считают «феноменальным сознанием» как таковым [6, с. 6]. Мышление, согласно этому взгляду может «сопровождаться различными феноменальными состояниями сознания - внутренняя речь и визуализация того 
или иного вида», однако они отрицают, что мышление само по себе является модусом феноменального сознания, и что «оно имеет иной или особенный феноменальный характер сравнительно с телесными или перцептивными состояниями» [6, с. 6].

Далее Bayne отмечает, что различие между двумя взглядами на феноменальное сознание важно для определения подходов к единству сознания. Консервативная точка зрения, согласно которой феноменальное сознание и нефеноменальное сознание это два существенно разных вида сознания, в решении вопроса о единстве сознания "нуждается в объяснении единства» не только для этих двух видов сознания, но также единства между ними [6, с. 7]. Принимая либеральную точку зрения, согласно которой все виды сознания по сути феноменальное сознание, Вауnе выделяет в этой логике три типа единства: 1) субъективное единство, определяемое отнесенностью ментального опыта к своему «Я» в синхронии и диахронии; 2) репрезентативное единство, объединяющее ощущаемые, воспринимаемые, переживаемые, мыслимые и т.д. объекты в одном интенциональном поле»; 3) феноменальное единство, связанное, согласно Вауnе, со всем объемом проявлений сознания ("fully unified) и обозначенное автором понятием «ко-сознание» (соconsciousness) [6, с. 9-10]. По приведенным в книге характеристикам косознание весьма сходно с рефлексией, однако сам Вауnе не использует этого понятия, предпочтя ему хорошо известную метафору потока сознания.

В современной русскоязычной философской и научной литературе проблематизация, постановка и проектируемые решения существенно иные [1]. В отстаиваемой нами двухфакторной модели сознания (социально-коммуникативная парадигма) тема единства сознания присутствует имплицитно [1]. Психологическое единство сознания в предложенной нами теоретической модели сознания может быть эксплицировано пересечением двух (в случае единичного субъекта) или множества условных трехмерных пространств коммуникативного и инстауративного сознания. Компонентами, соответственно, выступают: коммуникативный контакт, информационная коммуникация, рефрлексивно-смысловая коммуникация, личностный выбор, творческая самоактуализация, созидательная самореализация.

Первые два компонента коммуникативного сознания позволяют установить сам факт наличия единства по третьему компоненту коммуникативного сознания и первому компоненту инстауративного сознания. Соответствие рефлексивно-смыслового модуса коммуникативного сознания и модуса личностного выбора инстауративного сознания позволяет говорить о психологическом единстве сознания на одном из двух уровней - внутренней или внешней репрезентации в отношении индивидуального субъекта. В случае группового 
субъекта о единстве можно говорить с учетом определенного статистического критерия.

Подводя итог проведенному анализу, можно сделать следующие выводы:

1. Проблема осознанности и единства сознания становится особо актуальной в условиях современных глобальных динамичных изменений в экологии, политике, здравоохранении, образовании, социальной и культурной жизни во всем мире.

2. Подготовка и принятие управленческих решений на всех уровнях власти и их исполнение предполагает множество согласованных позиций, обусловленных диспозиционными, социально-перцептивными, аффективными, когнитивными и поведенческими характеристиками лиц, готовящих и принимающих решения, а также исполняющих эти решения. Вопросы единства сознания в этом контексте приобретают главенствующее значение.

3. Индивидуальная психологическая жизнь человека состоит из периодической смены привычных, не вполне и в полной мере осознаваемых форм активности. Нарушения единства сознания, как правило когнитивный диссонанс, аффективная амбивалентность и др. Особые или измененные состояния сознания и другие нарушения единства сознания личности в ряде случаев требуют конкретной профессиональной психологической помощи. Современная наука о сознании представляет новый обширный материал для соответствующей практической работы.

4. Современные технологические достижения в изучении мозга и нейронных коррелятов сознания позволяют полагать, что единство сознания человека обеспечивается и достигается не только социальными, социальнопсихологическими, индивидуально-психологическими факторами, но также нейропсихологическими. Разработка программ искусственного интеллекта, а в постановочном плане искусственного сознания, определяет необходимость моделирования ситуации единства vs дезинтеграции искусственно поддерживаемого сознания.

5. Категориальный и типологический подходы к постановке и проектированию решений проблемы сознания позволяют выявлять качественные отличия в англоязычных и русскоязычных исследованиях сознания, в том числе, и в вопросе единства сознания. Культурно-языковая научная традиция в одном случае, в связи со значительным периодом ориентации на поведение вне сознания (бихевиоризм), в относительно короткое время накапливается весьма масштабный фрилософский и научно-экспериментальный массив новейших разработок; в другом - отошедшем от явных идеологических ограничений, существенно расширяется и амплифицируется научно-теоретический и научно-прикладной психологический массив новейших результатов. 


\section{Литература}

1. Акопов Г.В. Категория сознания в современной психологии. Самара: Изд-во 000 «Порто-принт», 2019.

2. Назаретян А.П. Блеск и нищета биоцентрической экологии: к 50-летию Римского клуба // Историческая психология и социальная история. № 1 , 2018. с. 5-38.

3. Лотман Ю.М. Семиосфера. СПб. Искусство -СПб», 2010. с. 534.

4. Ревонсуо А. Психология сознания / Пер. с англ. СПб.: Питер, 2013.

5. Чалмерс Д. Сознающий ум: В поисках фрундаментальной теории. Пер. с англ. М.: УРСС; Книжный дом «ЛИБРОКОМ», 2013.

6. Bayne T. The Unity of Consciousness. Oxford University Press, 2012.

7. Block N. Confusion about a Function of Consciousness // Behavioral and Brain Sciences.Vol. 18, № 2, 1995, pp.227-247.

8. Dienes Z., Perner J. Representation, problems // The Oxford Companion Consciousness / Ed. By Tim Bayne, University Press. 2009, pp. 567-571.

9. Gennaro R.J. The Consciousness Paradox. Consciousness, Concepts, and Higher-Order Thoughts. A Bradford Book. The VIT Press/ Cambr., Massachusetts, London, England, 2012.

10. Honderich T. Actual Consciousness. Oxford University Press, 2014.

11. Horst S. Beyond Reduction: From Naturalizm to Cognitive Pluralizm //Mindand Matter. Vol.12, № 2, 2014, pp. 227-247.

12. Kriegel U. Subjective Consciousness A Self- Representational Theory. Oxford University Press. New York, 2011.

13. Putnam H. (1988). Representation and Reality. Cambridge. Mass.: MIT Press.

14. Revonsuo A. Binding problem // The Oxford Companion Consciousness / Ed. By Tim Bayne, Axel Cleeremans, Patrick Wilken. Oxford University Press. 2009, pp. 101-105.

15. Searle J.RThe Mystery Consciousness. New York: New York Review Books, 1997. 


\section{UNITY OF CONSCIOUSNESS IN MODERN PHILOSOPHICAL AND SCIENTIFIC RESEARCH}

Akopov G.V. (Samara State University of Social Sciences and Education, Samara, Russia)

The article examines the problem of consciousness unity in the context of modern consciousness studies. The article presents various points of view related to different approaches to identification of consciousness and determination of its structure are. The article analyzes the solution to the problem of consciousness unity presented in Tim's Bayne monograph. In the article we outline the author's approach to solving the problem of consciousness unity in the logic of socialcommunicative paradigm and two-factor model of consciousness. The article shows the possibility of a broad actualization of consciousness unity problem not only at the individual level of consciousness, but also in micro-, meso-, macro-group dimensions.

Keywords: consciousness unity, consciousness theories, phenomenal consciousness, subjectivity, representation, communication, instauration. 